\title{
Instituting a group component to a final exam
}

\author{
Thomas J. Wenzel ${ }^{1}$ Emily D. Niemeyer ${ }^{2}$ \\ Published online: 10 February 2020 \\ (C) Springer-Verlag GmbH Germany, part of Springer Nature 2020
}

\section{Introduction}

Most college courses culminate in a final written exam that students complete individually for a grade. The final exam often has a cumulative portion as well as questions on topics covered since the previous in-term exam. Whereas in-term exams are given back to the students with feedback so there is the potential for the students to rectify misunderstandings, final exams typically do not provide an opportunity for such feedback. We have often had students visit our offices wanting to see how they performed on the final exam, but their primary concern is usually what grade they received and not a desire to understand topics where they lost credit on the exam. It seemed unfortunate to us that the final exam could not serve as a final learning opportunity for students as well as an evaluative opportunity for instructors. In an attempt to alter this situation, we have both instituted a group component to the final exam in some of our courses (Fig. 1). Since each of us used a different format for the final, we will describe both of our approaches herein.

\section{Separation Science course}

The undergraduate analytical chemistry curriculum at Bates College consists of two courses, one titled Separation Science, and the other Analytical Spectroscopy and Electrochemistry. The first half of the Separation Science course is a rigorous coverage of chemical equilibrium. The second half is a

Thomas J. Wenzel

twenzel@bates.edu

Emily D. Niemeyer

niemeyee@southwestern.edu

1 Department of Chemistry and Biochemistry, Bates College, Lewiston, ME 04240, USA

2 Department of Chemistry and Biochemistry, Southwestern University, Georgetown, TX 78626, USA thorough coverage of fundamental aspects of chromatography including different categories of liquid chromatography (steric exclusion, ion exchange, high performance) and gas chromatography. Other aspects of analytical chemistry such as statistics, sampling, sample preparation, method validation, and the need for standardization are covered in the laboratory associated with the Separation Science course and an advanced level Measurement Laboratory course.

The structure of the Separation Science course is highly collaborative. Students are assigned to groups at the beginning of the term and work together every class period on worksheets that develop the topics being covered [1, 2]. Students also work in groups in the laboratory on a semester-long project that is carried out with a chromatographic method. Therefore, students have a lot of experiences working collaboratively with their classmates by the time of the final exam. The use of these in-class worksheets on equilibrium and chromatography has been previously described [3]. Materials used for the equilibrium [4], chromatography [5], and laboratory components [6] of the Separation Science course are freely available to others through the Analytical Sciences Digital Library under the Creative Commons Copyright.

The final exam for the Separation Science course is $2 \mathrm{~h}$ long and is a comprehensive evaluation of the chromatography unit. Prior to the inclusion of a group component, the final exam consisted of questions that spanned the range of cognitive levels within a learning taxonomy such as Bloom's taxonomy [7, 8]. Some questions were lower level items that could be answered through memorization. Others required them to apply knowledge (e.g., prediction of retention order; prediction of effect of experimental changes on peak broadening, resolution, and analysis time; selection and justification of the best variable to alter to improve resolution of overlapped peaks). Students previously used the 2 -h period to complete individual responses to the questions.

Use of a group format for the final exam was adopted in 2018 and repeated in 2019. I talked with the class in advance to let them know that there would be a group component of the 


\section{Traditional final exam}

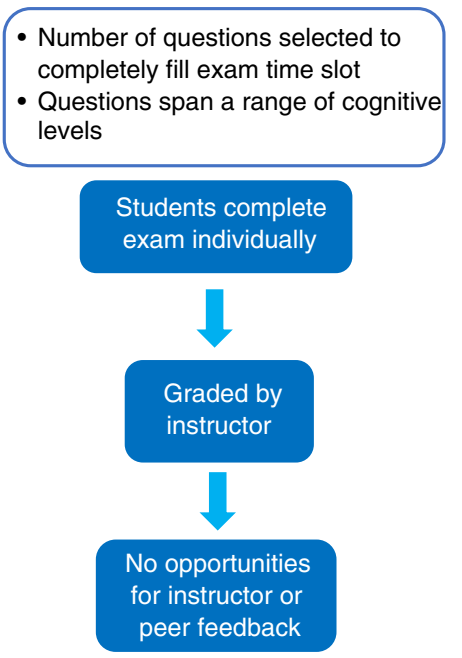

\section{Final exam with group component}

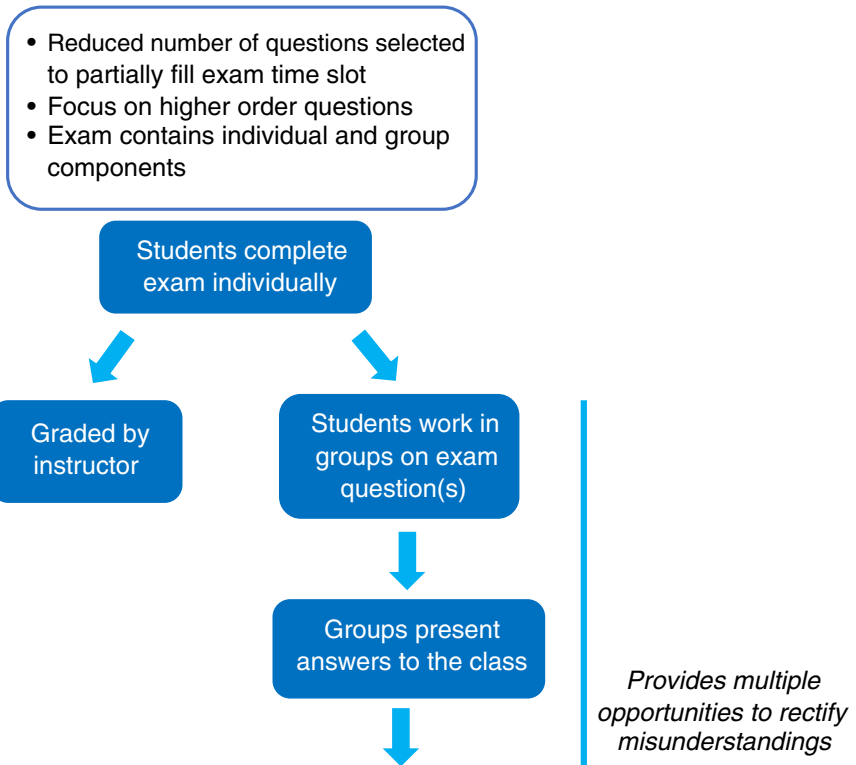

Class discusses

answers and students

reach consensus

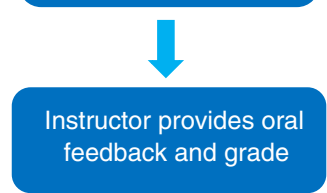

opportunities to rectify misunderstandings

Fig. 1 Summary of a traditional final exam versus a final exam with an added group component

final. Also, I described my reasons for using a group component of the final and how the process would work. One was my desire to use the final exam as a last chance for them to better learn the material we had covered in the chromatography portion of the course. The other was my belief that at some point in their future careers, they would participate in a situation where a group of people charged with solving a problem or deciding a future course of action would need to discuss options and reach a final group decision. The group component of the final would give them practice at reaching consensus.

With the group component, I reduced the number of questions on the final exam and only included higher level questions. Students were given $1 \mathrm{~h}$ to work individually on the exam and turn in a set of written answers for grading. These grades counted for half of the total grade on the final. The class, which each year has had 12 students, was then divided into three assigned groups. Groups were constructed to have students of differing abilities based on their prior exam scores and my in-class observations. Each group was given a third of the questions on the exam and had 15 min to write short answers to their questions on a section of the board. I then picked a question and one or more members of the group with that question had to explain their answer to the class. The class had to discuss the question and eventually arrive at a consensus answer to submit to me for a grade. I tried to maintain a blank expression during the discussion so as to not indicate whether the discussion was on the right track. Once they had submitted an answer, I let them know whether it was correct and why it was either correct or incorrect. Because of the challenging nature of the questions, in both years, the group grade has always been higher than any of the individual grades but neither class got a perfect score.

A gratifying observation has been the robust discussion that has taken place during the group component of the exam. There were some questions where the class quickly reached consensus. There were others where there was a considerable debate. During the most highly debated questions, there were times when other students went up to the board to write their thoughts and rationale for their answer. One year the class could not reach consensus on a question and decided to take a vote. The outcome was seven to five in favor of the correct answer and, even with a small majority, they decided to submit that answer for grading. Both years have had at least two occasions where the majority of the class initially favored the wrong answer, only one or two students favored the correct answer, and those one or two students explained their rationale to the entire class, which eventually became convinced to 
submit the correct answer. In each occasion, as those in the majority listened to their explanation, a few changed their minds and then provided additional rationale for why they now agreed with the one or two students who were correct in their view. Especially interesting, but likely coincidental, is that each year I had an occasion where the single student who favored the correct answer was the person who I would characterize as the shyest person in the class who had shown the least propensity to want to contribute to their group discussions throughout the term. Faced with the prospect of having their final grade impacted, these students felt empowered in the group discussion to get their views out there.

For problems where there was substantial disagreement about the final answer, I found it was necessary to limit the discussion time and request submission of a final answer for grading. I did make sure to allow sufficient time for all different points of view to be expressed but, mindful of the clock, indicated that they needed resolution on an answer to submit.

Student response to the group portion of the final exam has been uniformly positive. In follow-up discussions with students in both years, they talked about the group final being the most important and memorable aspect of the course. Students expressed how the engaged nature of their discussion of the questions demonstrated how much they had learned. Some also indicated that it was the first time they felt like chemical professionals.

I have taught the Separation Science course for almost 30 years. On a couple of occasions, I have had a student who far exceeded the abilities of the other students in the course and everyone else in the class was cognizant of the unique abilities of that student. This was not the case in the 2 years with the group final. With such a student in the class, I could imagine that the group component of the final might not work so well as everyone might just look to that one student for what they feel will likely be the correct answer. As mentioned earlier, the class format over the entire semester involves student group work and many of the questions on the worksheets are open ended and require recall and application of prior knowledge. Students in the course become accustomed to initially connecting inappropriate prior knowledge to answer a question or proposing the wrong answer to a question. That situation has mitigated the likelihood that the entire class will put undue influence on the answers of one particular student for the group component of the final.

\section{Instrumentation in Environmental and Biological Analysis course}

At Southwestern University, we offer a one-semester analytical chemistry course, Instrumentation in Environmental and Biological Analysis, that is required for chemistry majors and is an upper level elective for biochemistry and environmental studies students. As the only lecture course in our curriculum focusing solely on analytical chemistry, the class first provides an introduction to the discipline through such topics as calibration methods and analytical figures of merit. We then discuss chromatographic theory, separation methods (e.g., gas and high-performance liquid chromatography; capillary electrophoresis), mass spectrometry, and molecular spectroscopy - all with a particular focus on environmental and biologically relevant applications. Topics such as basic statistical analyses, extraction methods, and sample preparation are introduced in a separate project-based lab course, the Advanced Laboratory in Analytical Chemistry.

As part of a larger grant-funded pedagogical initiative, the Instrumentation course was completely re-designed in 2015 to incorporate student-centered active learning. Small groups (3 students each; 4 groups total) are assigned at the beginning of the semester and the groups collaborate on worksheets or other activities [9] during each class period. For some topics such as capillary electrophoresis and gas chromatography, students are assigned a short reading prior to class to provide them with foundational knowledge of the subject. In-class activities then expand upon the reading by encouraging students to use chemical principles to further understand and explain the topic or to apply their knowledge to new situations through problem solving. For other topics such as chromatographic theory and calibration methods, students come to class with little prior knowledge then work collaboratively on POGIL (process-oriented guided inquiry learning) style worksheets [10] that encourage them to construct their own understanding of a particular subject. Throughout the semester, working effectively with other students to cooperatively solve problems is emphasized as an important aspect of the course and is also articulated as an expected learning outcome on the course syllabus. In fact, the quality of each student's participation in group work activities during the course is assessed at the end of the semester and contributes to a portion of their final grade. In addition to their class participation, students are also assessed through weekly homework assignments, primary literature article assignments, two in-class examinations, and a final exam.

Prior to 2018, the final exam for the course was structured similarly to the in-class exams but was longer. Over half of the final exam was based on new material (covered since the last in-class test) with an emphasis on application questions such as selecting the detector best suited for a particular chromatographic analysis or predicting the elution order of a group of analytes. The exam also included higher order questions requiring students to evaluate analytical data and reach conclusions along with some lower order questions (e.g., asking students to explain the operation of a particular instrument component). At Southwestern, final exams are scheduled for $3 \mathrm{~h}$ and the test was designed with a sufficient number of questions (usually around 20) that most students required the full time to complete the test. 
Because of the emphasis on group work in my Instrumentation course, I was intrigued with the idea of adding a group component to the final exam for the class. I first suggested the idea to the students in my course in the middle of the Fall 2018 semester. At that point, they had been working with their group members for about 2 months and were comfortable expressing and debating their ideas within the classroom setting. However, the in-class exams for the course were all completed individually, so students were concerned about how the grading would work. I explained that they would complete an individual written exam during the first $2 \mathrm{~h}$ of the final and it would count toward $75 \%$ of their exam grade. Students would then spend the next hour working collaboratively in their regular groups to answer a subset of questions from the written exam, present their answers to the class, have the opportunity to discuss, and revise their answers; then, all receive the same group grade (counting 25\% of their final exam score). I also provided my rationale for adding a group component to the final exam: my wish to make an important assessment both more collaborative in nature and better aligned with a central aspect of the course, the focus on small group work. We further discussed the option as a class and the students were interested to try it.

For my final exam with a group component, I reduced the overall number of questions to allow students to complete the written portion of the test within $2 \mathrm{~h}$. Compared with my previous final, I maintained a similar mix of questions for the first part of the exam-primarily application questions but with a few lower order questions - and created a second section containing four multi-part higher order questions that focused on key topics we had discussed throughout the course (e.g., Beer's Law, chromatographic theory, calibration, and a summative question that provided students with a set of chemical problems then asked them to select the most appropriate instrumental technique for an analysis and explain their rationale). After submission of the written portion of the exam, students convened within their regular groups and each group was assigned one of the four problems from the second section of the test. Students in the four groups were given $15 \mathrm{~min}$ to work collaboratively on the questions, and each group was provided with a poster-size self-stick easel pad and markers to record their answer. I circulated through the classroom while the groups were working and although I provided clarification when groups had questions, I did not facilitate their discussions. Each group then had $\sim 10$ min to present their answer to the class, discuss it with their peers, revise their response if necessary, and decide on a final answer. I then provided immediate feedback on their answer and assigned a point total for each question. I set a timer during this portion of the final to ensure that we stayed on task since lively discussion followed each of the group presentations and my assessment of their answers.
Because the groups had already been working together all semester, the students felt comfortable discussing their ideas and responding to feedback from their peers. As a result, even before the full-class discussion, the quality of answers was much better-with more nuanced analyses and greater attention to detail- than what I later found when grading the written individual exams. For each of the four questions, the groups modified and further improved their answers after feedback from their peers, debate, and discussion. Although the answer quality was better when compared with students' individual exam responses, the class still did not earn a perfect score on the group component of the final. However, the average for the group component $(91.5 \%)$ was substantially higher than the average grade for the same questions on student's individual exams (69\%). This difference in scores also highlights one of the most rewarding aspects of the group final: I heard so many "aha moments" as students came to a new or better understanding of a particular concept while talking in their groups, as a class, or responding to my feedback once their final answers had been submitted.

My students also reported a positive experience with having a group component added to their final exam. Some were initially apprehensive since the format was quite different than any they had experienced previously but they enjoyed the interactive nature of the final as well as the opportunity that they were given to correctly answer questions that they had missed on their individual exams (which also helped to improve their grades). Students noted that being able to think through the questions individually during the written portion of the test was particularly helpful for the group component. They also appreciated having the opportunity to learn from others in the classroom while working together to determine the best answer to a question. Reflecting on the experience, I felt it was important that the students had been working in groups consistently throughout the semester and had developed a supportive and close-knit community. Their strong camaraderie formed a foundation for their success working collaboratively on a high-stakes end of the semester assessment. The challenging nature of the questions was also a key aspect of the final since it spurred considerable discussion and debate among both the groups and the full class. Although the questions were difficult, scaffolding similar open-ended higher order questions throughout the semester through inclass activities, homework assignments, and in-class exams helped students rise to the challenge. One difficulty that I encountered was administering the group component of the final to a student in my course who had academic accommodations to receive extra time when taking exams. However, I was able to individually work with the student to take the written final during a longer testing slot earlier in the day which allowed the student to participate in the group portion of the exam with the rest of the class. 


\section{Concluding comments}

We both have had the benefits of rather small classes so an obvious question is whether an instructor could use a group final in a larger class. Considering our own exams, with more students, we would still assign groups of three or four students but assign each group fewer questions (or if assigning a single question, limit the number of parts) to be responsible for answering and reporting out. This approach would actually shorten the time needed for groups to write an initial answer and lengthen the time available for reporting out. It would still be possible to have the students conduct a whole-class discussion to reach agreement on a final answer to submit for grading. With especially large classes, decision-making might be facilitated through the use of a personal response system. The system could be set up with a yes/no response, and after someone stated the answer under consideration for submission, students could respond. Alternatively, if multiple answers were under discussion, the possibilities could be numbered and students could respond to the number they favored most.

Funding information This work received financial support from the United States National Science Foundation through grant numbers 1624898 and 1624956.

\section{References}

1. Wenzel TJ. Anal Chem. 1995;67:470A-5A.

2. Wenzel TJ. Anal Chem. 1998;70:790A-5A.

3. Wenzel TJ. Anal Bioanal Chem. 2011;400:637-40.

4. Chemical equilibrium. https://community.asdlib.org/ activelearningmaterials/chemical-equilibrium/. Accessed 13 Jan 2020.

5. Separation science. https://community.asdlib.org/ activelearningmaterials/separation-science/ . Accessed 13 Jan 2020.

6. Separation science: chromatography projects. https://community. asdlib.org/activelearningmaterials/separation-sciencechromatography-projects/. Accessed 13 Jan 2020.

7. Bloom BS. Taxonomy of educational objectives: the classification of educational goals: handbook I, cognitive domain. New York: Longmans, Green; 1956.

8. Anderson LW, Krathwohl DR, Bloom BS. Taxonomy for learning, teaching and assessing, a revision of Bloom's taxonomy of educational objectives. New York: Longman Publishing Group; 2000.

9. For examples, see: Handelsman, J.; Miller, S.; Pfund, C. Scientific teaching; W.H. Freeman: New York, 2007; pp. 23-46.
10. Lantz J, Cole R. Analytical chemistry: a guided inquiry approach instrumental analysis collection. New Jersey: Wiley; 2015.

Publisher's note Springer Nature remains neutral with regard to jurisdictional claims in published maps and institutional affiliations.

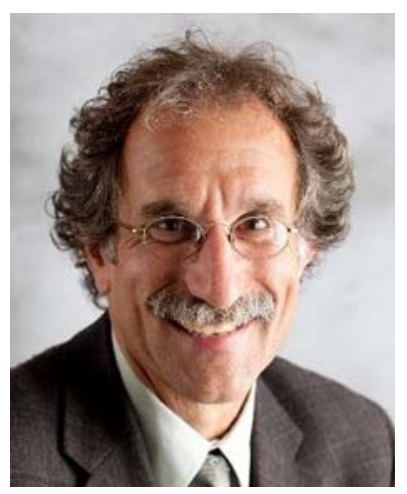

Thomas J. Wenzel is the Charles A. Dana Professor of Chemistry at Bates College in Lewiston, Maine, USA. His research accomplishments were recognized with the 2010 American Chemical Society National Award for Research at an Undergraduate Institution. $\mathrm{He}$ is active in efforts to reform the undergraduate analytical chemistry curriculum to include inquiry and project-based experiences. His educational activities have been recognized through the George C. Pimentel National Award in Chemical Education from the American Chemical Society (2020) and the J. Calvin Giddings Excellence in Education Award from the Analytical Division of the American Chemical Society (1999). More information about his activities can be found at http://www. bates.edu/chemistry/faculty/thomas-wenzel.

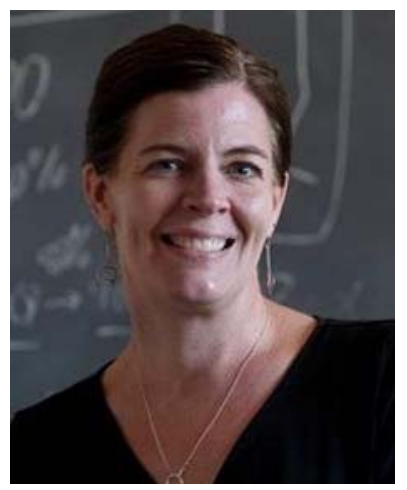

Emily D. Niemeyer is Professor of Chemistry and the Herbert and Kate Dishman Chair in Science at Southwestern University in Georgetown, Texas, USA. As the Program Director for Southwestern's Inquiry Initiative, she successfully oversaw a transition to an inquiry-based curriculum across the institution's science departments while significantly expanding undergraduate research opportunities for underrepresented students. She teaches a wide range of courses in analytical, environmental, and introductory chemistry as well as classes for non-science majors. She is an active researcher with undergraduate students and further details of her accomplishments can be found at https://www.southwestern.edu/live/profiles/25709-emily-niemeyer. 